\title{
Performance values - an artistic research perspective on music performance anxiety in classical music
}

\author{
Francisca Skoogh ${ }^{1 \star}$ and Henrik Frisk ${ }^{2}$ \\ ${ }^{1}$ Malmö Academy of Music, Lund University; ${ }^{2}$ Royal College of Music in Stockholm
}

\begin{abstract}
Music performance anxiety (MPA) has been studied mainly within the field of psychology and has been defined as a sub-type of social anxiety. Musicians suffering from MPA are commonly referred to individual psychological treatment, but the condition is not yet researched from an artistic perspective. The hypothesis put forward in this article is that the issues concerning MPA are part of a complex system of interactions between performance values and perfectionism and that musicians in general are not given the necessary tools to tackle the anxiety. One of the challenges is that Western classical music performance has many built-in values that need to be problematized and researched in order to address the problems with MPA. Hence, MPA is not to be considered as solely an individual problem but should rather be seen as the result of a wider structural issue related to the commodification of classical Western music and its focus on perfection and virtuosity. This article gives an example from the field of artistic research on how it is possible for the performer herself to develop methods to understand and emotionally regulate the impact of perfectionism in Western classical music.
\end{abstract}

Keywords: Music performance anxiety; perfectionism; artistic research; Western classical music

Recieved: November, 2018; Accepted: February, 2019; Published: April, 2019

\section{Introduction}

Performance anxiety is a well-known problem for many musicians and other performing artists, as well as for professionals in other fields. When the tension becomes debilitating to the musician it is referred to as music performance anxiety (MPA).

\footnotetext{
^Korrespondanse: Francisca Skoogh, Musikhögskolan i Malmö, Box 8203, 20041 Malmö. Email: francisca.skoogh@mhm.lu.se

(C) 2019 F. Skoogh and H. Frisk. This is an Open Access article distributed under the terms of the Creative Commons Attribution 4.0 International License (https://creativecommons.org/licenses/by-nc/4.0/), allowing third parties to copy and redistribute the material in any medium or format and to remix, transform, and build upon the material for any purpose, even commercially, provided the original work is properly cited and states its license. 


\section{F. Skoogh and H. Frisk}

MPA is present in everyday life of many musicians, as a part of wider health issues concerning musicians' health. It has been pointed out that health issues in general receive limited attention in higher musical education and that institutions should play a central role in increasing the levels of student health literacy (Araújo, et al., 2017 , n. p.).

In this article we will present a brief review of MPA and continue to examine MPA through a self study by author Francisca Skoogh, within her research project. Departing from perfectionism in Western classical music this article outlines how performance values affect the authors and possibly other musicians and in what way musicians can develop and use emotional coping strategies to process them.

- 1. A perfect performance rests on knowledge of and understanding for the tradition and the score (Goehr, 1992, p.100).

- 2. A perfect performance must be original enough to stand out from prior performances and traditions and the musician needs to "... process and execute complex musical information with novel artistic insight, technical facility, and a keen awareness of audiences' expectations" (Williamon, 2004, p. 3).

Our primary interest is concerned with the performer's psychological understanding of these somewhat contradictory performance values.

The aim towards exceptional performance is a natural component in most musician's life. Western classical musicians strive to reach a perfect performance or an overall excellence in performance (Williamon, 2004). In music such as in the opening of the fourth piano concerto by Beethoven pianists search for the perfectly balanced chords in order to fulfil the needs that the music and the tradition suggests, and they dream of succeeding with the infamous coda in Chopin's fourth Ballade. "Practice makes perfect" is a motto built into the profession. As such it captures the aim of working towards the perfect performance and points to the main method; practicing is the key to the perfect performance. This methodology is a rarely challenged attitude that has a great impact on the life of classical musicians.

What is sought after in Western classical music are original interpretations, but with utmost respect for the text as is commonly referred to as Werktreue. "Performances and their performers have respectively been subservient to works and their composers" (Goehr, 1992, p. 231). Though rightfully debated the concept of Werktreue is still an active regulative force. As an ideal, in combination with the vision of a flawless performance, it certainly has the power to fuel music performance anxiety (MPA), but it also puts creative constraints on the individual musician.

Failed performances are not a topic commonly discussed by musicians and artists. Only a few examples can be found, although a recent one is of particular interest in this context. Yundi Li, one of the world's top pianists performed Chopin's piano concerto no 1 , in 2015, and experienced a memory lapsus severe that the conductor had to restart the movement. After the concert a social media storm broke out with disappointed fans demanding their money back, and criticizing the way the 
pianist had handled the situation. The audio clip is not available anymore; in the world of classical music damage control is of utmost importance. What remains is a statement issued by Li confirming the incident:

“... As a pianist, I know that no matter what, my performance on stage must be perfect, any kind of explanation is insufficient. Thank you for your comments" (as cited in Ejinsight, 2015).

The need to apologize might be considered a positive action on the part of Li, but the statement is telling with regard to the current state of Western classical music performance. A different commentary on what is considered failure, or a performance result is presented in the section "The perfect performance" in this article. Deriving from concert experiences from a $\mathrm{PhD}$ project it is possible to draw the conclusion that at least part of what constitutes the conditions that result in MPA is not solely related to the music in and of itself or to individual vulnerability but may be related to some of the conditions musicians must comply with.

Perfectionism in classical music is obviously connected to the important notion of the virtuoso (Frisk, 2017), but it also has an immediate relation to the development of a performance culture with a strong focus on recordings. The possibility to edit recorded performances, even on a note to note basis, is likely to have furthered the expectation of flawless musical performances. Kenny (2011, n. p.) states that "with respect to music performance, the standards may be imposed, not only by perceived significant others, but by the availability of perfect recordings of the repertoire against which the performer and the audience compare a live concert performance".

Western classical music has long been regarded as structurally more complex than other genres conveying "a greater range of human cognition and emotion" (Becker, 1986, p. 342). The romantic era is commonly considered as the golden age, and the tradition is kept alive by conservatories, symphony orchestras, record companies, artist's agencies, public and private funding organizations, radio broadcasting companies (though to a lesser degree in recent years) and many other agents. The romantic and still influential idea that music in some respects has intrinsic values that go beyond whatever social or political frameworks it is otherwise bound to has been challenged many times, in particular within experimental music and, more recently, in the field of artistic research.

\section{The research field of artistic research}

Is the kind of knowledge artistic researchers want to produce different from the knowledge produced in traditional disciplines? Kjørup (2012) discusses the field in relation to the scientific community and argues that research done by artists through their own creative process should be of interest to society (p. 26), i.e. also outside of the field of artistic practice. Artistic research (AR) in music is an emerging field that gives the musician - in a broad sense, including all professional music practice the ability to acquire knowledge through their practices. Results from AR may be 


\section{F. Skoogh and H. Frisk}

applied both within artistic practices and in a broader context. AR can have an impact on and in fields as diverse as interpretation and analysis of musical works, behavioural practices and historical contexts, social practices. Significant for the field is the fact that it is the first-hand experience of the musician that guides the research. The idea that artistic expressions and artistic practice have a distinct knowledge dimension that nevertheless is comparable to other fields of knowledge is an important aspect of AR. Hence, the practice of the musician is the central arena for the research and the methodological challenge is to develop approaches in which the musician can be both in the practice and research it at the same time.

Several composers and performers within AR have been addressing questions concerning musical interpretation and performance in the classical performance tradition. The ERC project ME21, led by Paulo de Assis in Gent, Belgium (Orpheus Institute, 2018) is a project in this category. ME21 can be said to embody a novel version of Susan Sontag's famous phrase "against interpretation" (2013). Both projects depart from canonical works in the tradition of Western classical music for solo piano, but expand to philosophical texts, videos, live electronics and other mediums as well. Through the project the score of Beethoven's Diabelli variations becomes living matter, ready for the artist to interpret anew, from many perspectives, and not limited to traditional musical parameters such as tempo, dynamics and phrasing.

Swedish composer Anders Hultqvist has created several projects that question the limits between interpretation and composition. In 2011 he presented two new works, a staging of Beethoven's fifth symphony and a new composition drawing on Albinoni's Adagio. As described by Hultqvist "the goal is to re-read and re-set the music and relieve it from some of the cultural layers and interpretational rituals that conventionally have been assigned to the pieces" (Hultqvist, 2013).

Catherine Laws, pianist and musicologist, specializes in contemporary music, and explores the innate drama of interactions between performer, instruments and audience. She has several ongoing artistic projects in this field, framed within the research cluster at the Orpheus Institute titled "Performance, Subjectivity and Experimentation" together with Stefan Östersjö, William Brooks, and David Gorton (Orpheus Instituut, 2014).

These examples do not address MPA specifically or problems with perfectionism in general, nor do they engage in problems where the artist is caught in the search for the perfect performance (to some extent ME21 by Paulo de Assis approaches this area). However, they do point to how new artistic frames for performance can be crucial for musicians to explore and develop their position as expressive, critical musicians as opposed to repetitive, perfect entertainers. The field of MPA has not been explored within AR to any greater extent. A search for articles on MPA in the Research Catalogue, an established international database for AR and in Journal for Artistic Research, does not give any substantial results, suggestive of the fact that this field is not yet explored. 


\section{The perfect performer}

Music Performance Anxiety and Perfectionism - an overview

\section{Music Performance Anxiety}

Music performance anxiety is the experience of marked and persistent anxious apprehension related to musical performance that has arisen through underlying biological and/or psychological vulnerabilities and/or specific anxiety-conditioning experiences. It is manifested through combinations of affective, cognitive, somatic, and behavioural symptoms. It may occur in a range of performance settings but is usually more severe in settings involving high ego investment, evaluative threat (audience), and fear of failure. It may be focal (i.e. focused only on music performance), or occur comorbidly with other anxiety disorders, in particular social phobia. It affects musicians across the lifespan and is at least partially independent of years of training, practice, and level of musical accomplishment. It may or may not impair the quality of the musical performance (Kenny, 2009b, p. 433).

Brodsky (1996) had already in the nineties reviewed studies on MPA and criticized them on five different aspects: definition of terms, assessment, sampling, epidemiology and treatment, proposing that this might have led to the wrong way of tackling MPA. He also reconceptualizes MPA as a broader concept, within the scope of career and occupation, rather than relating it to psychological ill health. Even though new interventions and studies have been performed in the last 20 years, Brodsky's concern that researchers "have led performing arts medicine practitioners and researchers down the wrong avenues" (Brodsky, 1996, p. 96) must still be noticed.

A precise prevalence of music performance anxiety (MPA) amongst musicians is unfortunately difficult to establish due to the lack of research, to less rigorous validity and reliability in the surveys used in early research and the difficulties of defining MPA (Kenny, 2011, p. 7). Kenny's definition as cited above, is one of the most precise in recent years. Many of the available music performance anxiety scales used to map MPA are adaptations of existing anxiety measures, and have therefore no theoretical basis (Kenny, 2011, p. 27). Research surveys have focused on different cohorts of musicians for example orchestral musicians, operatic choral singers, and music students etc. limiting the results to these groups. Even with these methodological limitations in mind the problem of MPA becomes apparent when aproximately $15-23 \%$ of orchestral musicians suffer from severe or persistent music performance anxiety (Fishbein \& Middlestadt, 1988; van Kemenade, van Son, \& van Heesch, 1995). Further, there is evidence that solo performances showed higher MPA scores than ensemble performances. (Brugues, 2011, p. 102). There seems to be no relation between having professional experience or not, for example great artists such as Pablo Casals has reported having MPA. However one recent study concerning psychophysiological responses (agari responses) examined levels of low frequency 


\section{F. Skoogh and H. Frisk}

$[\mathrm{LF}] /$ high frequency $[\mathrm{HF}]$ ratio during the performance with an audience between amateur and professional pianists. The results showed that although the levels of LF/ $\mathrm{HF}$ ratio increased in both groups the increment size was larger for the professional players (Bannai, Imanishi, \& Oishi, 2018).

Is perceived performance anxiety experienced more or less, among different types of musicians, different genres including classical, jazz, and popular? The results in a study by Papageorgi, Creech and Welch (2013) showed that Western classical musicians reported higher levels of performance anxiety and that solo performance generated more anxiety compared to group performances. Another conclusion was that the traditionally formal context of classical performance may create additional pressure and increase anxiety levels. "Further research is needed to investigate how genre- specific contexts might influence musical performance anxiety so that strategies to deal with the demands of performance can be adapted accordingly" (Papageorgi et al., 2013 , p. 36). Though more research is needed, this is nevertheless an indication that there is something in the general context of Western classical music that gives rise to negative feelings.

\section{Perfectionism}

Perfectionism in psychological theory and research, has been described and studied from both negative and positive aspects. The term is considered to be multidimensional but has proven to be difficult to conceptualize and define (Flett \& Hewitt, 2002). Two major dimensions of perfectionism have emerged; perfectionistic strivings and perfectionistic concerns (Stoeber \& Otto, 2006). Perfectionism as a maladaptive coping mechanism has also been described and can be a response to psychological distress or loss of control in a problematic life situation. It has been connected with anxiety, depression, obsessive-compulsive disorder and eating disorders. Perfectionism has been researched in behavioural contexts and perfectionistic behaviour has been analysed as constituted not by one, but rather several different personality traits. Nine unidimensional personality traits that contribute to perfectionistic behaviour have been found and summarized as: "Order, Satisfaction, Details and Checking, Perfectionism toward Others, High Standards, Black and White Thinking about Tasks and Activities, Perceived Pressure from Others, Dissatisfaction, and Reactivity to Mistakes" (Stairs, Smith, Zapolski, Combs, \& Settles, 2012, p. 162).

As a personality trait, perfectionism can be measured with the Dutch Multidimensional Perfectionism Scale of Hewitt, Flett, Turnbull-Donovan and Mikail (1991) which has also been used to study musicians and other performing artists (Mor \& Day, 1995). They found that both self-oriented and socially prescribed perfectionism is connected to performance anxiety. Perfectionism was found to be not only linked to debilitating anxiety but also to the lack of facilitating anxiety (p. 219). They conclude that cognitive behavioural interventions can improve levels of negative perfectionism but 
the perfectionistic standards may be difficult to modify because striving for perfection is a socially acceptable behaviour and it is often demanded in certain occupational groups, such as professional performers. Socially prescribed perfectionism would be even more difficult to modify if significant others nd (sic) audience members did not indeed expect perfection. (Mor \& Day, 1995, p. 221)

There is an inherent tendency toward perfectionism in competitive environments where goal orientation dominates, such as sports, in academia and very much so in the classical music tradition. Studies on musicians and perfectionism have focused on its connection to for example performance anxiety, focal dystonia and eating disorders. Kapsetaki and Easmon (2017) conducted a survey study on the prevalence of eating disorders in musicians and evaluate their relation to perfectionism, stress, anxiety and depression. One of their findings was that perfectionism was higher in classical compared to non-classical musicians.

Perfectionism seems to have a negative impact even among very young musicians. One study showed strong correlation between MPA and perfectionism between ages 10 and 17 (Patston \& Osborne, 2016). There was also a significant gender difference and the study notes that female musicians experience "a steeper and more intense developmental trajectory than males. The developmental pathways of MPA and perfectionism are consistent in late childhood between males and females" (p. 47). The third finding, showed that levels of MPA and perfectionism increase with years of experience. This, despite the fact that older students plausibly should have more experience with their instruments, feel more comfortable with their playing, and therefore feel less anxious. Researchers concluded that these findings raises further questions such as: are the increases due to the students or the teachers, is it a normal consequence of the psychological development of children, or are teachers somehow influencing these conditions (p. 47)? MPA is frequently considered to be an individual problem and a range of interventions have been suggested to musicians to address the problem, but unfortunately, several of these are based on studies not always methodologically strong enough (Matei \& Ginsbourg, 2017). Examples of these interventions include cognitive-behavioural therapy (CBT), multimodal interventions, acceptance and commitment therapy (ACT), the use of beta-blockers, virtual reality exposure training and psychological skills training. A majority of these are treatments directed to individuals, consistent with the notion that MPA is a psychological disorder.

Perkins, Reid, Araújo, Clark and Williamon (2017) investigated health issues amongst musicians, such as lifestyle and health-related attitudes and behaviour. They found that music students had higher levels of wellbeing and lower fatigue than comparable population within the same age group. However, the study also showed that engagement in health responsibility and stress management was low, they had high perfectionistic strivings, limited use of coping strategies, poor sleep quality, and low self-rated health. In the study they encourage a further look into the "core cultures of conservatoires", and for musicians themselves to take greater responsibility for their health (Perkins et al., 2017, n. p.). 


\section{F. Skoogh and H. Frisk}

\section{The perfect performance}

The performer's approach

The PhD project in artistic research by concert pianist and licensed psychologist Francisca Skoogh, is concerned with the psychological processes that are part of musical interpretation of classical music, but is not often, if ever, addressed by musicians themselves.

Musicians suffering from stage fright are most often referred to psychological research and solutions drawn from it, mainly as a way of coping with fear of performing and how to reduce it. They are rarely introduced or encouraged to artistic ways of approaching the act of performing in a health promoting, proactive process, but rather as a reactive response to something dysfunctional.

Skoogh's artistic research focus is on the traditions and ceremonies of classical performance, such as the piano recital, and how they affect her psychologically as a performer. Skoogh examines what happens in the various performing situations presented in Western classical music and why she experiences negative emotions when preparing to perform and while performing, and how she can address and regulate these emotions. The project aims to develop new approaches to classical concert performance. This includes experimentation with the concert format and how, as a consequence, interaction with the audience can become more dynamic. These aims can be further defined through the following research questions:

- What artistic methods can be used to challenge the performance traditions and conventions in classical concert tradition?

- How can introspection based on theories in the field of psychology be used in an artistic analysis and development of musical performance?

One example of this is her cooperation with composers Staffan Storm and Kent Olofsson revolving around the Sonata op. 11 by Schumann (Pianovisions, 2018, Olofsson \& Skoogh, 2018). The project aim at exploring the performance of classical iconic repertoire through the theories and psychoanalytic concepts of play, present moment and vitality affects (Stern, 2010, Winnicott, 2005).

As suggested in the introduction, in the tradition of Western classical music there is a paradoxical demand to respect the work and preserve its tradition while at the same time renew it in ways that avoid repetition. A performance that fails to introduce something that is new in relation to the tradition may fall into the trap of merely producing generic repetitions of well-known pieces. A performance that is flawed, perhaps due to the artist's efforts to express something new is not possible. Turning to other fields of knowledge, in particular Donna Haraway's "A cyborg manifesto" (1984) has been a way for the authors to emotionally regulate, analyse and process one particular negative concert experience as described next.

Skoogh performed Rachmaninov's third piano concerto in the programming season of 2016 with conductor Stefan Solyom, and Helsingborg Symphony Orchestra. 
Her own opinion of the first performance in 2016 of the concerto was that it was a good first try at rendering it the importance and weight it demands. She suffered no major performance anxiety in connection to these performances. Two years later she was asked to perform it again with conductor Leif Segerstam and Norrkoping Symphony orchestra, in April 2018. This time the pianist felt more immersed in the piece, the material appeared in a different light, as is often the case with pieces you repeat after some years. To be able to perform not just repeat a classical canonical piece like this, several levels of personal input, or authenticity (Kivy, 1995, p. 123) is needed. But during rehearsals she lost her sense of direction, she also lost track of personal decisions on what she wanted to do with the music and started fearing every new moment, theme, or solo entrance in a way she could not have anticipated beforehand. Playing by heart became impossible and playing with score is problematic in the Western classical piano performance tradition (Ginsborg, 2004, p. 123). Feelings of complete inadequacy, fear and hopelessness became superordinate and never really left during the two concert performances signified by severe performance anxiety. Skoogh makes the following reflection on the experience:

\begin{abstract}
If I could have chosen between being myself at the moment of performing the Rachmaninov concerto or switching to be the flawless cyborg version of me, I would without a doubt have chosen the cyborg. Why? Out of respect for the work, out of respect to the audience, the cyborg would have been the perfect solution, without fear and without strong feelings of discomfort. This is at least what I would have done then, but now, a few months later, the experience made me reconsider classical performance traditions and realizing that my own thoughts of the performance have little to do with the experience of the audience. It has been emotionally valuable to reflect on this process, by describing my experience, by not reducing it and as I use to do in the past, move onto the next concert. Haraway proposes the cyborg as a solution, a relief, to overbridge gender and to reconstruct identity (Haraway, 1985, p. 100). While struggle to understand how to perform music in a largely unconceivable social and political musical landscape, becoming a machine may in fact appeared to be a sensible refuge. In my case it is translated into the choice between performer as human or performer as perfection. And here, much to my great surprise, on the contrary, to communicate the emotional range and greatness of Rachmaninov's third piano concerto, the audience had no need for a cyborg. Somehow, I have always tried to destroy myself and create a neutral performer. My experienced failure received by others as a non-failure is a paradoxical part of my practice. I have sought to melt together two conflicting performance values that constituted my inner "perfect performance" into a cyborg me. This affected my performance experience negatively, but I was "saved" by the reception of my performance, the interaction with the audience, in a way that should not, be possible according to demands of perfection in the classical music industry. To paraphrase Haraway, this experience made me want to explore further how to be a human on stage, rather than the cyborg I thought I had to be. (Reflective note)
\end{abstract}

The next morning, she was met by the following review by one of Sweden's leading classical music critics:

With Franciska Skoogh as soloist we were brought right into a flow that in the most humane way tears up what is hidden and exposes the locked-up emotions and hard-wired pain on its unstoppable urge to move ahead. Skoogh and the orchestra 


\section{F. Skoogh and H. Frisk}

made this music noisy, trickle and sing in a remarkable way. And leading to the incredible progression of chords, in the last few bars that this evening truly sounded like the world's most beautiful melody. The fact that the audience cried openly was not surprising. The triumph afterwards was deafening. (Martin Nyström, 2018; our translation)

All musicians evaluate their performances, often their latest ones but of course also revisiting performances made in the past. It is an ongoing evaluation that without doubt must have an emotional dimension. In this process it would be of interest to understand what extent emotional regulations are used and if we could proceed to use it in an artistic development in order to also develop the performance culture itself. Two emotional regulation strategies, cognitive reappraisal (changing thoughts concerning an emotional event) and expressive suppression (changing the responsive emotional behaviour in connection to the event) can be used to analyse the live concert experience above (John \& Gross, 2004, p. 1304). The work leading up to this article is an example of a cognitive reappraising strategy. It is also a preparation for similar concert experiences in the future, possibly changing the emotional impact. Skoogh's live performance and the rehearsal period of Rachmaninov's third concerto as described above, constitutes a suppressive behaviour not uncommon during concert situations. Suppression does not reduce the negative impact of a negative emotion, rather it accumulates and rests unresolved. It also decreases cognitive resources, much needed while performing this concerto, which can result in memory impairment (John \& Gross, 2004, p. 1307).

Very few pianists express, analyse, share or try to change the effects of striving for the perfect performance. Instead, if they are not able to cope with performing and the values attached to it, experiences are often silenced and perhaps even considered an individual disorder. Could it be that the aim of perfection is a misguided expression of respect for the work, the audience and the concert situation? How can musicians artistically begin to address the overwhelming sense of responsibility towards the composer, the Werktreue-ideal, the audience, and the live situation as something terrifying?

\section{Discussion}

\section{Musicians and performance values}

Musicians may be aware of the two contrasting values proposed in the introduction of this article but what can they do to explore, criticize and alter the nature of this sometimes paralyzing dichotomy? The latter is closely associated with the possibility to develop an authentic identity as a performer, but always in relation to the score, both following the instructions and not doing so (Kivy, 1995, p. 45).

Drawing from the author's concert experience presented above, we think it is fair to suggest that there is a danger that the classical music performer is reduced to a vessel for the artwork, caught between the need of originality, perfection and fear of 
failing. The cybernetic metaphor used above is one way to process the difficulties that musicians face on stage. The process of analysing a concert experience through (in this case) a text is an example on how this particular performer chose to artistically understand, emotionally regulate and process the experience. It is also a continued process rather than a time limited therapeutical treatment and it makes further use of the material derived from this analysis into the performer's upcoming concert projects.

Our concern is that not enough researchers critically discuss performance values as a source of MPA and that they do not consider artistic methods as possible partners in research. On the contrary, in the attempt to prepare musicians to the dominating belief that the audience have extraordinary demands, some research risks to bolster negative and perfectionistic aspects of performing. Examples of this include a 2014 study examining the possibilities of performance simulation at the Royal College of Music stating that "[e]exceptional musical performances require an ability to execute complex physical and mental skills on stage under intense pressure and public scrutiny" (Williamon, Aufegger \& Eiholzer, 2014). And in the introduction of a study by Yoshie, Kudo, Murakoshi and Ohtsuki (2009), the following statement can be found on how social-evaluative performance situation affects subjective, autonomic and motor stress responses in pianists: "In a real musical world, however, every single performance in public can either boost or wreck musicians' career, which causes them higher levels of psychological stress." (Yoshie, et al., 2009, n. p.). Papageorgi, Creech and Welch (2011) suggest that "The formality of the context within which classical musicians operate perhaps contributes to creating additional pressure and, subsequently, increasing anxiety levels" (p. 36). Their conclusion is that further research is needed, but again, to help musicians adapt to the demands of performance, not questioning the demands themselves, nor the culture they are part of. Such statements, even though partly true, may inadvertently reinforce norms and values that are hampering musicians.

It should be pointed out, that treating MPA through individual therapy is still viable, but this must not prevent us from seeing the structural and social causes. By involving musicians in the process of changing stage performance and by addressing the problems of the industry of classical music may contribute to a better environment for classical music. Making it possible for musicians to express and develop artistic methods that can empower their performances and move away from perfection as entertainment towards the many other qualities of an experimental and vaster field of classical music may be another obvious way to improve. If the context of classical performance contributes to heightened levels of anxiety, then it is probable that the classical music educational system moves in the same direction, being a provider of artists for the industry. An urgent responsibility lies therefore within the conservatory to critically address these issues. This is given some support in a recent study, where the authors encourage a further look into the "core cultures of conservatoires" (Perkins et al., 2017). 


\section{F. Skoogh and H. Frisk}

Few performers share negative experiences and how they deal with them. Perhaps by revealing any weakness artists risk having fewer concert engagements. Organizers want reliable artists that will not succumb to the pressure. There are some outstanding performers such as Stephen Osbourne (as cited in Hewitt, 2014) and Renée Fleming (as cited in Hewitt Morland, 2013) that talk openly about perfectionism, stage anxiety and they are important role models for artists. Musicians themselves must be an addition to the "messenger matters" (Pecen, Collins \& MacNamara, 2017, n. p.) and be part of "a bespoke blend of performance psychology specialists, inspirational speakers and self-help methods might be considered to circumvent the stigma of psychological interventions and encourage take-up."

\section{Exploring MPA through artistic research}

How can research help musicians themselves have more courage to experiment with performances that are not aiming towards perfection? Artistic research can give inspiring examples on how to do so and may be used as a developmental tool for musicians to create change through self-analysis and by promoting the personal perspective on how to formulate new processes both directly on stage but also off stage. Perkins et al., (2017) examined the health and well-being amongst conservatoire students within the institutional context. By using a thematic analysis, a set of enablers and barriers were found. Among the key enablers was the environmental enabler, such as enjoyable experiences of performance as well as strong relationships and communities. It is therefore important for musicians to be encouraged to develop this in real concert settings.

Very few within the larger institutions such as classical symphony orchestras, the symbol of the classical music industry, are moving in experimental directions fearing audience will not agree with the changes. The director of Helsingborg Symphony Orchestra, Fredrik Österling (The Guardian, 2018), frequently poses critical questions concerning the tradition of classical music and construct programs with, for this rigid context, unusual programming. This is not unproblematic however and considered to be risky in the struggle of survival of orchestras.

As exemplified in this article one possibility for addressing performance values through artistic practice is to describe experienced failures, compare them to the listeners' experience, and relate oneself as an artist as a whole and connected to a system of values. This reappraisal process is a psychological openness that may be a valuable tool for musicians. Departing from their own practical experiences classical musicians can gain insights, for example, by connecting it to other fields in arts and science, on how the outside forces of their practice influences them. This allows for the possibility to synthesize their artistic knowledge through the process and may contribute to the development of the field in general. By decentring the notion of perfection experienced by the performer and in addition making it a property of a system of values, the musician's psychological understanding of the task may change. 
One possible artistic method is to move away from the notion of the perfect work and performance, and approach interpretation as a motion that continuously participates in creating new versions of the work.

As a relatively new field artistic research focuses, among other things, on the possibility of research as a tool for artistic development. When psychologists study musicians from an MPA perspective, the aim is to reduce anxiety with psychological methods and therapy. Musicians studying their own practice, using musical expression, communication and repertoire (to name a few possibilities) are likely to find different and complementary ways of coping with performance values. Eventually, structural difficulties brought forward by musicians themselves, not noticeable to the outside research community, can be slowly dismantled. Ultimately, an interdisciplinary study involving both artistic researchers and music psychologists may prove to be an effective means to tackle the problems of MPA in both conservatoires and in artistic practice.

\section{About the authors}

Francisca Skoogh, pianist, doctoral student in Artistic Research, lic. Psychologist Department of Artistic Research, Malmö Academy of Music, Lund University. As of 2018 she is a member of the Royal Swedish Academy of Music. She is a clinical psychologist and gives lectures on topics like stage performance. She has made several recordings with both chamber and solo music.

Henrik Frisk, PhD and Docent in Artistic Research, associate professor Royal College of Music in Stockholm. His research is concerned with improvisation, interactivity and experimental electroacoustic music. Henrik has contributed to the Routledge companion to research in the arts, and is the co-editor and contributor of Acts of Creation, an anthology on artistic research supervision.

\section{References}

Araújo, L. S., Wasley, D., Perkins, R., Atkins, L., Redding, E., Ginsborg, J., \& Williamon, A. (2017). Fit to Perform: An Investigation of Higher Education Music Students' Perceptions, Attitudes, and Behaviors toward Health. Frontiers in Psychology, 8. http://doi:10.3389/fpsyg.2017.01558

Bannai, K., Imanishi, T., \& Oishi, K. (2018). Amateur and professional piano players' music performance anxiety and psychophysiological responses. In J. Vopava, V. Douda, R. Kratochvil \& M. Konecki (Eds.), Proceedings of the Multidisciplinary Academic Conference (pp. 46-50). CSVTS - Czech Association of Scientific and Technical Societies.

Novotného lávka 5, Prague 1, Czech Republic. Retrieved from https:/www.researchgate.net/profile/Suzanne_El_ Takach/publication/323996357_Using_drawings_to_investigate_Lebanese_in-service_science_teachers \%27_ views_about_teaching_and_learning_process/links/5ab78ac9aca2722b97ce74c4/Using-drawings-toinvestigate-Lebanese-in-service-science-teachers-views-about-teaching-and-learning-process.pdf

Becker, J. (1986). Is Western Art Music Superior? The Musical Quarterly, 72(3), 341. Retrieved from http:// ludwig.lub.lu.se/login?url=http://search.ebscohost.com.ludwig.lub.lu.se/login.aspx?direct=true $\& d b=e d s j s$ $\mathrm{r} \& \mathrm{AN}=$ edsjsr. $948146 \&$ site $=$ eds-live $\&$ scope $=$ site

Bellam. M. (2018-05-31). Swedish orchestra turns homophobic hate mail into music. The Guardian. Retrieved from https:/www.theguardian.com/world/2018/may/31/swedish-helsingborg-orchestra-turnshomophobic-hate-mail-music 


\section{F. Skoogh and H. Frisk}

Brodsky,W. (1996). Music performance anxiety reconceptualized. Medical Problems of Performing Artists, 11(1), 8898. Retrieved from https://www.researchgate.net/publication/285675638_Music_performance_anxiety_ reconceptualized_A_critique_of_current_research_practices_and_findings

Brugués, A. O. (2011). Music performance anxiety—part 1. A review of its epidemiology. Medical problems of performing artists, 26(2), 102-105. Retrieved from http://ludwig.lub.lu.se/login?url=http://search.ebscohost. com/login.aspx?direct=true $\& \mathrm{db}=$ edo $\& \mathrm{AN}=62554465 \&$ site $=$ eds-live $\&$ scope $=$ site

Ejiinsight. (2015). Pianist Li Yundi apologizes for poor performance in Seoul. Retrieved 2018-11-15 from http:/www.ejinsight.com/20151103-pianist-li-yundi-apologizes-poor-performance-seoul/

Fishbein, M. and Middlestadt, S., E. (1988). Health and occupational correlates of perceived occupational stress in symphony orchestra musicians. Fournal of Occupational Medicine, 30(9), 687-692. doi.org/10.1016/00224375(89)90047-9

Flett, G. L., \& Hewitt, P. L. (2002). Perfectionism and maladjustment: An overview of theoretical, definitional, and treatment issues. In G. L. Flett \& P. L. Hewitt (Eds.) Perfectionism: Theory, research, and treatment. (p. 5-31). Washington, DC: American Psychological Association.

Frisk, H. (2017) Hell is full of musical amateurs, but so is heaven, Seismograf, http://seismograf.org

Ginsborg, J. (2004). Strategies for memorizing music. In A. Williamon (Ed.) Musical excellence: strategies and techniques to enhance performance, (p. 123-141). New York: Oxford University Press.

Goehr, L. (1992). The Imaginary Museum of Musical Works: An Essay in the Philosophy of Music. New York: Oxford University Press.

Haraway, D. J. (1985). A Cyborg Manifesto. University of Minnesota Press.

Hewitt, I. (2014-06-26). Stage fright: classical music's dark secret. The Telegraph. Retrieved from https://www. telegraph.co.uk/culture/music/classicalmusic/10920925/Stage-fright-classical-musics-dark-secret.html

Hewitt, P. L., Flett, G. L., Turnbull-Donovan, W., \& Mikail, S. F. (1991). The Multidimensional Perfectionism Scale: Reliability, validity, and psychometric properties in psychiatric samples. Psychological Assessment: A Fournal of Consulting and Clinical Psychology, 3(3), 464- 468. doi.org/10.1037/1040-3590.3. 3.464

Hultqvist A. (2013). "Who creates the creator" - and the limits of interpretation? Fournal for Artistic Research. Retrieved 2018-11-18 from http://jar-online.net/exposition/abstract/who-creates-creator-and-limitsinterpretation

John, O. P., \& Gross, J. J. (2004). Healthy and Unhealthy Emotion Regulation: Personality Processes, Individual Differences, and Life Span Development. Fournal of Personality, 72(6), 1301-1334. https://doi.org/10.1111/ j.1467-6494.2004.00298.x

Kapsetaki, M. E., and Easmon, C. (2017). Eating disorders in musicians: a survey investigating self-reported eating disorders of musicians. Eating and Weight Disorders-Studies on Anorexia, Bulimia and Obesity, 1-9. doi: 10.1007/s40519-017-0414-9

Kenny, D. T. (2010). The role of negative emotions in music making in performance anxiety. [Electronic resource] In P. Juslin \& J. Sloboda (Eds.), Handbook of Music and Emotion: Theory, Research, Applications. New York: Oxford University Press. Retrieved from http:/www.oxfordscholarship.com.ludwig.lub.lu.se/ view/10.1093/acprof:oso/9780199230143.001.0001/acprof-9780199230143-chapter-16

Kenny, D. T. (2011). The psychology of music performance anxiety. New York: Oxford University Press.

Kivy, P. (1995). Authenticities: Philosophical Reflections on Musical Performance. New York: Cornell University Press.

Kjørup, S. (2010). Pleading for plurality: Artistic and other kinds of research. In M. Biggs \& H. Karlsson (Eds.), The Routledge companion to research in the arts (pp. 54-73). New York: Routledge.

Matei, R., \& Ginsborg, J. (2017). Music performance anxiety in classical musicians - what we know about what works. BfPsych. International, 14(2), 33-35. http://doi:10.1192/S2056474000001744

Mor, S., \& Day, H. I. (1995). Perfectionism, control, and components of performance anxiety in professional artists. Cognitive Therapy \& Research, 19(2), 207-225.

Morland, P. Terror behind a rising curtain: Why do talented performers get stage fright? Independent. (201304-26). Retrieved from https:/www.independent.co.uk/arts-entertainment/books/features/terror-behinda-rising-curtain-why-do-talented-performers-get-stage-fright-8587709.html

Nyström, M. Konsertrecension: Franciska Skoogh på Göteborgs konserthus. Dagens Nyheter. (2018-04-08). Retrieved from https://www.dn.se/kultur-noje/konsertrecensioner/konsertrecension-franciska-skoogh-pagoteborgs-konserthus/

Olofsson, K. \& Skoogh, F. (2018-04-10) Collaborative Play. Retrieved from https://vimeo.com/284362674

Orpheus Instituut. (2014). Performance, Subjectivity and Experimentation. Retrieved 2018-11-18 from https:// orpheusinstituut.be/en/projects/performance-subjectivity-and-experimentation 


\section{Performance values - an artistic research perspective on music performance}

Orpheus Institute. (2018). MusicExperiment21. Retrieved 2018-11-18 from https://musicexperiment21.eu/ people/paulo-de-assis/

Papageorgi, I., Creech,A., \&Welch, G. (2013). Perceived performance anxiety in advanced musicians specializing in different musical genres. Psychology of Music, 41(1), 18-41. doi.org/10.1177/0305735611408995

Patston, T., \& Osborne, M. S. (2016). The developmental features of music performance anxiety and perfectionism in school age music students. Performance Enhancement $\mathcal{G}$ Health, 4(1-2), 42-49. doi:10.1016/j.peh.2015.09.003

Pecen, E., Collins, D. J., \& MacNamara, Á. (2018). “It's Your Problem. Deal with It.” Performers' Experiences of Psychological Challenges in Music. Frontiers in Psychology, 8. http://doi: 10.3389/fpsyg.2017.023742374

Perkins, R., Reid, H., Araújo, L. S., Clark, T., \& Williamon, A. (2017). Perceived Enablers and Barriers to Optimal Health among Music Students: A Qualitative Study in the Music Conservatoire Setting. Frontiers In Psychology, 8. http://doi: 10.3389/fpsyg.2017.00968

Pianovisions (2018, December 9). Pianoafton med Francisca Skoogh på Konstakademien i Stockholm. Retrieved from https://www.youtube.com/watch?v=cOvM_e6CUE0

Sontag, S. (2013). Against interpretation and other essays. UK: Penguin Modern Classics, Penguin Books.

Stairs, A. M., Smith, G. T., Zapolski, T. C., Combs, J. L., \& Settles, R. E. (2012). Clarifying the construct of perfectionism. Assessment, 19(2), 146-166.

Stern, D. N. (2010). Forms of vitality: Exploring dynamic experience in psychology, the arts, psychotherapy, and development. New York: Oxford University Press.

Stoeber, J., \& Otto, K. (2006). Positive conceptions of perfectionism: Approaches, evidence, challenges. Personality and social psychology review, 10(4), 295-319.

van Kemenade, J. F., van Son, M. J., \& van Heesch, N. C. (1995). Performance anxiety among professional musicians in symphonic orchestras: A self-report study. Psychological Reports, (77), 555-62. doi.org/ 10.2466/pr0.1995.77.2.555

Williamon, A. (2004). A guide to enhance musical performance. In A. Williamon (Ed.) Musical Excellence (p. 3-18). New York: Oxford University Press.

Williamon, A., Aufegger, L., \& Eiholzer, H. (2014). Simulating and stimulating performance: introducing distributed simulation to enhance musical learning and performance. Frontiers in Psychology, 5. http:// doi:10.3389/fpsyg.2014.00025

Winnicott, D. W. (2005). Playing and Reality. London: Routledge. (First published in 1971).

Yoshie, M., Kudo, K., Murakoshi, T., \& Ohtsuki, T. (2009). Music performance anxiety in skilled pianists: effects of social-evaluative performance situation on subjective, autonomic, and electromyographic reactions. Experimental Brain Research, 199(2), 117-126. doi.org/10.1007/s00221-009-1979-y 